\title{
LIVROS DIDÁTICOS E EPISTEMOLOGIA DA HISTÓRIA: PERSPECTIVAS E ABORDAGENS DO CONHECIMENTO HISTÓRICO NA CULTURA ESCOLAR
}

\author{
TEXTBOOKS AND EPISTEMOLOGY OF HISTORY: \\ PERSPECTIVES AND APPROACHES OF HISTORICAL KNOWLEDGE IN SCHOOL \\ CULTURE
}

Éder Cristiano de Souza ${ }^{1}$

RESUMO: O presente artigo tem como proposta uma reflexão sobre livros didáticos, no sentido de analisar como apresentam elementos para identificar e compreender os pressupostos da área a que se destinam, a História. E, ainda, refletir sobre seus limites e possibilidades a partir de uma ideia mais abrangente de epistemologia da história, relacionada às finalidades educativas desse conhecimento. As indagações que orientaram a pesquisa foram as seguintes: como os livros didáticos promovem abordagens referentes à construção do conhecimento histórico e a formas de pensar a partir do tempo? Ao promover tais abordagens, de que forma poderíamos analisá-las do ponto de vista de uma pragmática da Educação Histórica? Tendo em conta essas questões, o artigo aprofunda a discussão sobre os limites e possibilidades de análise dos livros didáticos como produtos inseridos na cultura escolar, propõe uma discussão que relacione ensino e epistemologia da história. Por fim, a partir de um estudo exploratório sobre livros didáticos destinados aos alunos do sexto ano do Ensino Fundamental, evidencia como essas obras abordam a dupla natureza do conhecimento histórico, uma relacionada à construção do conhecimento e outra às suas finalidades educativas.

Palavras-Chave: Cultura Escolar. Livros Didáticos. Epistemologia da História. Educação Histórica.

\begin{abstract}
The present article aims to reflect about textbooks, in order to analyze how they present elements to identify and to understand the assumptions of the area to which they are destined, History. And also, to reflect on its limits and possibilities from a more comprehensive idea of

\footnotetext{
${ }^{1}$ Docente do curso de História da Universidade Federal da Integração Latino-Americana (UNILA), Foz do Iguaçu - PR e do Mestrado em História Social da Universidade Estadual de Londrina (UEL). Líder do grupo de pesquisas LEHAL - Laboratório de Pesquisas em Ensino de História na América Latina. E-mail: eder.souza@unila.edu.br.
} 
epistemology of history, related to the educational purposes of this knowledge. The questions that guided the research were: how do textbooks promote approaches to the construction of historical knowledge and ways of thinking from time to time? When promoting such approaches, how could we analyze them from the point of view of a Historical Education pragmatics? Taking into account these questions, the article deepens the discussion about the limits and possibilities of textbooks analysis as products inserted in the school culture, proposes a discussion that relates teaching and epistemology of history. Finally, based on an exploratory study on textbooks intended for students in the sixth year of elementary school, it shows how these works deal with the dual nature of historical knowledge, one related to the construction of knowledge and other to its educational purposes.

Keywords: Schoolar Culture. Textbooks. Epistemology of History. Historical Education.

\section{Introdução}

Ao tomarmos como referência o conceito de epistemologia, buscando o verbete em um dicionário de termos gerais, encontraremos duas definições básicas. A primeira traz o entendimento segundo o qual a epistemologia consiste numa reflexão geral sobre a natureza, as etapas e os limites do conhecimento humano. A segunda relaciona o conceito de epistemologia ao estudo dos postulados, conclusões e métodos dos diferentes ramos do saber científico. Em síntese, uma primeira definição mais abrangente sobre a natureza da própria ciência e uma segunda mais específica, relacionada aos pressupostos de cada área do conhecimento.

Partindo desse entendimento, o presente artigo subdivide-se em duas partes. Primeiramente, problematiza a relação que os manuais didáticos, a cultura escolar e as discussões em geral em torno do Ensino de História, estabelecem entre uma natureza epistemológica própria da História e suas finalidades, enquanto conteúdo de formação/motivação do ser e do agir dos indivíduos. Na sequência, apresenta um estudo empírico, de caráter exploratório, com livros didáticos, que revela certo distanciamento entre esses 
dois polos, quais sejam, a natureza própria da História num âmbito epistemológico e suas finalidades para a orientação da vida em sociedade.

Os livros e manuais didáticos são artefatos presentes de forma central na cultura escolar e, a partir dessas obras, diversas possibilidades se abrem às preocupações dos investigadores nas áreas da Educação e das disciplinas específicas. Entre tais possibilidades, as relações que os manuais didáticos estabelecem com o conhecimento de referência, seus pressupostos e estratégias didáticas, a dinâmica do mercado editorial, as políticas públicas de ensino, assim como as formas de apropriação e uso dessas produções pelos sujeitos envolvidos nos processos de escolarização.

No Brasil, a inserção dos livros didáticos na cultura escolar configura-se como resultante de ações governamentais, seja como manuais de orientação dos professores ou livros de estudo para alunos. Essa política teve origem com a criação do Instituto Nacional do Livro, em 1937, e a instituição da Comissão Nacional do Livro Didático, em 1938. Em 1985, o PNLD (Programa Nacional do Livro Didático), tornou-se um programa oficial de avaliação, aquisição e distribuição de manuais didáticos para as escolas públicas e vem se consolidando, desde a década de 1980, como instrumento de universalização e regulação da produção de manuais didáticos em âmbito nacional (CHAVES; GARCIA, 2011).

Assim, os livros didáticos são a principal ferramenta de trabalho dos professores na escola básica, e não é equivocado dizer que se trata de uma fonte elementar para estudo da cultura escolar. Faço essa afirmativa tomando como referência o conceito de cultura como a aglutinação das dimensões simbólica e material da produção humana, sob a lógica do movimento dialético, ou seja, cultura como ação e representação humana em movimento (WILLIAMS, 2003).

No caso de cultura escolar, refiro-me à concepção segundo a qual os processos de escolarização e a forma escolar produzem uma cultura própria, que sintetiza os processos de apropriação do conhecimento e sua conversão em conteúdo de ensino (JULIA, 2001). O livro didático representa uma 
dimensão específica da cultura escolar, que revela muito mais o que se intenciona do que o resultado em si do processo, tendo em vista que cultura envolve, também, apropriações e usos.

Dadas essas definições, apresento as indagações iniciais que guiam as reflexões do presente artigo: como os livros didáticos promovem abordagens referentes à construção do conhecimento histórico e a formas de pensar a partir do tempo? Ao promover tais abordagens, de que forma poderíamos qualificá-las do ponto de vista de uma epistemologia própria da pragmática da Educação Histórica?

Para elucidar essas questões, faz-se necessário definir dois termos não muito usuais nos debates sobre a presença do conhecimento histórico na cultura escolar. O primeiro refere-se ao fato de que entendemos por epistemologia a concepção segundo a qual todo conhecimento humano se constrói a partir de princípios e métodos fundamentados e, ainda que tais princípios e métodos possam sofrer mudanças ao longo do tempo, ontologicamente mantém um núcleo comum, constituindo a própria identidade disciplinar.

Já ao referir-se à pragmática da Educação Histórica, toma-se por base a ideia segundo a qual a reflexão sobre as práticas e metodologias de ensino, vinculadas a uma concepção específica e situada de aprendizagem histórica, contribuem para pensar princípios e processos de trabalho, no sentido de constituírem-se como pragmáticas vinculadas a certo arcabouço de fundamentação teórico-metodológica. Ou seja, para além da ideia de didática e metodologia de ensino, como processos educacionais gerais, entendo que há certa especificidade no ensino e na aprendizagem histórica, que podem direcionar ações e processos voltados a qualificar a aprendizagem histórica de forma situada, especifica em seus pressupostos e objetos (SCHMIDT, 2009).

Tendo em conta as referidas possibilidades de estudo dos manuais didáticos na cultura escolar, bem como sua importância como artefatos presentes de forma complexa nas relações de ensino e aprendizagem, o presente trabalho visa contemplar algumas preocupações de pesquisa, que 
podem ser sintetizadas a partir de uma questão específica: como os manuais didáticos abordam com a dimensão epistemológica da ciência histórica?

Para responder ao questionamento, o percurso definido para este artigo inicia-se por aprofundar a discussão sobre os limites e possibilidades de análise dos livros didáticos como produtos inseridos na cultura escolar. Na sequência, propõe uma discussão sobre o que se configuraria, especificamente, como uma abordagem epistemológica na ciência histórica, discutindo a ideia de um ensino que leve em consideração as especificidades deste conhecimento, para além de sua particularidade como ramo de pesquisas no interior das instituições científicas, visando à construção de uma pragmática da Educação Histórica.

Ao final, busca evidenciar alguns aspectos gerais sobre a forma e o conteúdo dos livros didáticos de História no que concerne à presença de questões epistemológicas, apresentando um estudo sobre um conjunto de obras didáticas, que permitem evidenciar formas através das quais se estabelecem relações entre os conteúdos dessas obras e a epistemologia da História. Por fim, já com caráter de considerações finais, apresenta algumas reflexões sobre possibilidades viáveis de se qualificar as obras didáticas no sentido de uma pragmática da Educação Histórica, visando o estreitamento da relação entre epistemologia e Ensino de História, com foco nos livros didáticos.

\section{Livros didáticos, Cultura Escolar e Educação Histórica}

Um aspecto central no que tange aos estudos sobre a cultura escolar (JULIA, 2001), é a centralidade da compreensão dos estudantes e professores como sujeitos que estabelecem relações com o conhecimento, e da presença dos manuais e demais recursos didáticos que expressam determinadas formas de compreensão e apreensão do conhecimento em âmbito escolar. Dessa forma, as relações entre indivíduos e sociedade, bem como a conceituação de cultura que direciona tais reflexões, são pontos centrais no âmbito das definições teórico-metodológicas que orientam os estudos e constatações dessa área. 
Nesse contexto, um conceito central é a concepção de cultura. Para Raymond Willians (2003), há, pelo menos, três definições do conceito de cultura: 1. Ideal - A cultura é compreendida em termos de perfeição humana, de um conjunto de valores partilhados e que se tornariam referências para o desenvolvimento dos indivíduos; 2 . Documental - Refere-se à massa de obras intelectuais e imaginativas que registram o pensamento e a experiência humana; 3. Social - Diz respeito a um determinado modo de vida, no qual certos significados e valores, seja em aspectos artísticos, institucionais ou comportamentais, são partilhados por um grupo.

Tais formas de compreensão do conceito de cultura, quando tratadas isoladamente, apresentam problemas, especialmente por se fecharem a partir da noção de "entidade percebida", ou seja, de um conjunto de elementos dados, sem que se perceba a dinâmica histórica e o aspecto relacional da cultura (WILLIANS, 2003). Por isso, o teórico opta por resgatar a ideia original do termo cultura, que se relaciona à ideia de cultivo, ou seja, não entende cultura como algo dado, pronto em acabado, mas como algo que se põe em movimento contínuo a partir das ações dos sujeitos no seu interior. A partir dessa concepção, os sujeitos agem e constroem significados, num processo de relações que configuram as experiências. Uma vez que "a sociedade não é apenas a casca morta que limita a realização social e individual. É sempre também um processo constitutivo com pressões muito poderosas, que são internalizadas e se tornam vontades individuais" (WILLIANS, 1979).

Toma-se, portanto, como referência a concepção de que a cultura se constitui como um conjunto de práticas e expectativas sobre a totalidade da vida, que direciona a autoimagem dos sujeitos, as atribuições de sentidos e sua distribuição de energia, dentro de um sistema de valores e significados vividos, experimentados como práticas que parecem confirmar-se reciprocamente, sendo constitutivas e constituidoras das experiências individuais (WILLIANS, 1979).

A cultura escolar se configura, então, como campo de manifestação de determinados objetivos e práticas de ensino, através dos quais os sujeitos se 
inserem num mundo social mais amplo, sendo que são também formados por essa cultura. Mas esses sujeitos constroem significados e estabelecem relações, num processo no qual trazem toda uma carga cultural, relativa ao espaço social e à geração aos quais pertencem que é confrontada e ressignificada no interior do espaço escolar e das práticas de escolarização.

Tal concepção de cultura escolar interessa também aos estudos sobre os manuais didáticos, uma vez que, segundo Chaves e Garcia:

[...] ao longo dos últimos cem anos, os livros ganharam força como um artefato da cultura escolar e foram incorporados de diferentes maneiras na cultura da escola; eles passaram a influenciar a educação no país seja do ponto de vista dos conteúdos de ensino, seja quanto às formas de ensinar, privilegiando concepções e abordagens, indicando estratégias e recursos e, portanto, contribuindo para definir elementos constitutivos do ensino nas diferentes disciplinas escolares (CHAVES; GARCIA; 201, p. 59).

Mais do que entender os manuais didáticos como guias passíveis de assimilação, por parte de professores e alunos, é importante perceber como eles se inserem no contexto amplo da cultura escolar. Isso significa dizer que um manual didático propõe-se a estabelecer uma aproximação dos sujeitos com os conhecimentos de referência, mas tal relação é complexa.

Quando se pensa nos processos através dos quais os livros didáticos inserem-se na cultura escolar, é preciso entender que tais obras sofrem influências variadas, chegando ao professor e aos alunos a partir de processos de escolhas, inseridos numa tradição seletiva da cultura. Dessa forma, disputas intelectuais, culturais e ideológicas podem ser compreendidas como fatores importantes nos processos de produção e distribuição dos livros didáticos. Os conhecimentos e referenciais teórico-metodológicos inseridos nesses materiais também não passam ao largo dessas questões (CHAVES; GARCIA, 2011).

Jean-Claude Forquin aponta como há um processo de seleção cultural de conteúdos a serem ensinados na escola, que é entendida como instituição social que cumpre a função de transmissão cultural. Trata-se de uma tradição seletiva que define e redimensiona conteúdos culturais, recondicionando-os e 
dando forma a uma cultura específica: a cultura escolar. Dessa forma, é possível definir a cultura escolar a partir de um conjunto de regras, saberes e práticas que configuram a escola, e que a ultrapassam, na medida em que ela age na e através da sociedade (FORQUIN, 1993).

Essa tradição seletiva define o que deve ou não ser transmitido culturalmente, selecionando determinados conteúdos e formas de abordagem, excluindo ou minimizando outros. Os estudos dos manuais didáticos podem, assim, constituir-se como material empírico em pesquisas que visem identificar tais processos de seleção no interior da cultura escolar, uma vez que:

[...] seu conteúdo expressa os resultados de um processo de seleção cultural, no qual são definidos tanto os significados da escolarização como o que se considera relevante ensinar. Mas não se trata de pensar que a escolarização se subordina apenas ao conjunto de normas que definem conhecimentos a ensinar; a cultura escolar inclui um conjunto de práticas que permitem a transmissão desses conhecimentos e a incorporação desses comportamentos (CHAVES; GARCIA, 2011, p. 9761).

Segundo Valls Montes (2001), os estudos sobre manuais didáticos precisam abranger reflexões que possam ir além daquilo que se expressa no conteúdo dos seus textos, pois a compreensão dos usos e apropriações dessas obras permite entender seus limites e direcionar estratégias com vistas a qualificá-los.

Um ponto de partida para essa preocupação consiste no fato de que estudos empíricos apontam que grande parte dos alunos sequer compreende o livro num nível elementar, pois não estabelece uma relação ativa e crítico reativa com os alunos. Assim, na concepção de Valls Montes, a análise do livro didático deve tomar como referência os estudos da chamada história das disciplinas escolares, pois seu marco teórico mescla diversas tendências, que possibilitam "adentrar à densa rede de representações e convenções estabelecidas e práticas escolares mais ou menos rotineiras, que condicionam o que acontece dentro das aulas ${ }^{2 *}$ (VALLS MONTES, 2001).

2 Tradução própria. 
Os manuais didáticos são, portanto, fontes poderosas de investigação. É possível considerar o grau de aceitação/difusão das obras, abordando as razões de sua aceitação ou rejeição, ampliar o conhecimento sobre os diversos usos dos diversos recursos disponibilizados pelas obras e averiguar o grau de eficácia alcançado pelos conteúdos dos manuais.

Além desses aspectos, que dizem respeito à presença e ao uso dos manuais didáticos na escola, sua análise também pode ancorar-se em observar o que Medeiros (2006) chama de "Economia Política do Livro Didático", que consiste em observar os processos de produção dessas obras e como esses são condicionados a uma complexa rede de relações. Essa rede envolve prioridades empresariais das editoras, tendências e limitações na ação dos autores, a atualização teórica do campo científico e, o que 0 autor considera preponderante, os interesses dos professores como clientes preferenciais, ou seja, como os principais compradores/consumidores dessas obras.

$\mathrm{Na}$ área de História, é relevante, também, pensar, como o estudo dos livros didáticos permite visualizar o que Raimundo Cuesta Fernandez chama de Código Disciplinar, definido como:

[...] una tradición social que se configura históricamente y que se compone de un conjunto de ideas, valores, suposiciones y rutinas, que legitiman la función educativa atribuida a la Historia y que regulan el orden de la práctica de su enseñanza. Alberga, pues, las especulaciones y retóricas discursivas sobre su valor educativo, los contenidos de su enseñanza y los arquetipos de práctica docente, que se suceden en el tiempo y que se consideran, dentro de la cultura dominante, valiosos y legítimos. [...] el código disciplinar comprende lo que se dice acerca del valor educativo de la Historia, lo que se regula expresamente como conocimiento histórico y lo que realmente se enseña en el marco escolar. Discursos, regulaciones, prácticas y contextos escolares impregnan la acción institucionalizada de los sujetos profesionales (los profesores) y de los destinatarios sociales (los alumnos) que viven y reviven, en su acción cotidiana, los usos de educación histórica de cada época (CUESTA FERNANDEZ, 1998, p. 8-9).

A partir dos estudos de Urban (2009) é possível observar o desenvolvimento do Código Disciplinar para a História no Brasil ao longo do 
século $X X$, dentro do qual se pode identificar princípios, definições, objetivos e métodos concebidos como fundamentais e adequados ao ensino de História. Nesse processo, a pedagogia, nas metodologias de ensino, a psicologia, nos fundamentos de aprendizagem, foram disciplinas predominantes e direcionaram as reflexões.

Jörn Rüsen (2007) considera essa "externalização e funcionalização da didática" uma concepção estreita da História. E acredita que é parte do escopo teórico-filosófico do trabalho com o conhecimento histórico refletir sobre as formas e funções que o saber histórico exerce na vida prática, bem como observar de que forma a aprendizagem histórica pode ser entendida e articulada com objetivos voltados a essa presença ativa da História na formação dos indivíduos. A partir desse referencial teórico e da ideia de rearticulação dos fundamentos da ciência da História com as preocupações em relação à aprendizagem histórica, torna-se possível propor estudos que articulem a intenção de ensinar História a partir de objetivos relacionados diretamente aos fundamentos do conhecimento histórico.

A pesquisa com manuais didáticos permite entender essa dimensão da relação estabelecida com o conhecimento por uma obra, que será utilizada por professores como referência na elaboração de seu trabalho e pelos alunos, como fonte de consulta e aprendizado. Na sequência, abordaremos de forma mais aprofundada os princípios e preceitos dessa pragmática da Educação Histórica, visando pensar nas possibilidades de indagar os manuais didáticos sobre suas abordagens em relação à epistemologia da História.

\section{Compreensão histórica e orientação da vida: por uma pragmática da Educação Histórica}

Peter Lee (2016) propõe que a pragmática da Educação Histórica destine-se ao desenvolvimento de uma literacia, ou alfabetização histórica, que pode ser subdividida em três objetivos, quais sejam: 1. Fazer como que seja desenvolvida uma compreensão disciplinar da história, ou seja, que os alunos 
reconheçam os conceitos fundamentais no processo de construção do conhecimento histórico; 2. Possibilitar a aquisição de disposições que derivam dessa compreensão e a impulsionam, tornando a História um conhecimento vicário, ou seja, relevante para a vida dos sujeitos; 3. Favorecer a construção de uma imagem do passado que permita aos indivíduos orientarem-se no tempo, ou seja, de um conjunto de conhecimento e referências históricas que favoreçam a compreensão e a ação no mundo presente.

Nesse sentido, Lee propõe objetivos que se relacionam a dois polos epistemológicos. Por um lado, a História como campo do conhecimento com regras e métodos próprios, que disciplinam as possibilidades de compreensão, interpretação e representação do passado, deve ser um conteúdo do aprendizado histórico. Por outro, a compreensão por si só destes conceitos e fundamentos não é suficiente, pois uma reflexão epistemológica mais abrangente sobre o conhecimento histórico reconhece sua presença como fator motivador das ações e intenções dos indivíduos, assim como base para a construção de compreensões e explicações sobre o mundo, favorecendo o agir e o pensar em relação ao mundo em que se vive.

Os objetivos para o Ensino de História relacionar-se-iam, então, a esse duplo caráter epistemológico da História. Contudo, se, por um lado, a compreensão da complexidade da construção das explicações históricas pode levar à uma postura crítica diante das versões simplistas e utilitaristas do passado. Por outro, ainda é limitada a compreensão sobre os mecanismos a partir dos quais os sujeitos adquirem disposições para defender uma racionalidade histórica na construção de suas posturas e visões de mundo.

Lee (2016) entende que a compreensão histórica é transformativa, ou transformadora, pois aprofunda pontos de vista e permite entender elementos como as diferenças temporais, a recorrente indeterminação e imprevisibilidade dos eventos, assim como a diferença entre ações individuais e movimentos coletivos, entre outras. Entretanto, considera a História uma conquista frágil, vulnerável a agendas interessadas em manipular o passado em nome de conquistas do presente. Assim, ressalta a dificuldade de se estabelecer, 
simultaneamente, conceitos fundamentais que devem ser aprendidos para um bom domínio dos conteúdos históricos e, ao mesmo tempo, um quadro abrangente do passado que seja suficiente para compreender e posicionar-se diante das demandas do presente.

Há um paradoxo elementar. Lee confia que a epistemologia da História, como ciência que transforma o passado em compreensível e inteligível a partir de determinados critérios e procedimentos, tem contribuições elementares para a vida dos sujeitos, pois os tornaria aptos a lidar com ideias mais abrangentes, fugindo ao senso comum e às constatações mais imediatas, que são mediadas por um olhar instantâneo e instintivo, condicionado pelo presente.

Entretanto, como ato educativo, fornecer um quadro de orientação histórica, a partir do qual os sujeitos possam se posicionar no mundo, entra em choque com a própria natureza investigativa e reflexiva da racionalidade histórica, pois se no fundo a História é construção humana, a seleção de conteúdos, previamente fixados para orientar os sujeitos, não deixa de ser uma construção definida externamente ao sujeito que o aprende, o que não deixaria, no fim, de ser uma forma de uso utilitarista da História, ou pelo menos deixaria margem para isso.

Esse caráter individual da construção do pensamento histórico como uma operação de identificar no passado certas explicações para a orientação da vida é uma reflexão central na obra de Rüsen (2001). Para o teórico alemão, há uma natureza própria do pensamento histórico que consiste no ato de se buscar, no passado, explicações que deem subsídios para a construção das identidades e ações dos sujeitos no presente.

Ao movimento de construção dessas referências de passado que explicam o presente e orientam expectativas de futuro, Rüsen chama de Consciência Histórica. Esse teórico classifica as formas de atribuição de sentido ao passado, operadas pela consciência histórica, a partir de quatro níveis: tradicional, exemplar, crítica e genética. Essas operações vão da forma mais elementar a mais complexa, sendo que na primeira o passado aparece como 
enraizado de forma natural no presente, visto como continuidade; na segunda o passado oferece extratos de experiência para serem seguidos como exemplos; na terceira há uma negação constante da presença e influência do passado nas decisões do presente; na última, o passado é reconhecido como outro tempo, e as rupturas e continuidades são identificadas, enquanto a tomada de decisões no presente passa a ser guiada pela ideia de mudança, sendo o passado influente, mas não mais determinante na construção das identidades e do agir dos indivíduos.

Entre Lee e Rüsen há uma coincidência no reconhecimento da utilidade do passado como elemento de orientação da vida. Entretanto, para Rüsen, essa utilização é inevitável, pois toda narrativa histórica consiste numa construção interessada de passado, que nasce das carências do presente, e são representadas para fazer sentido e interferir no presente. Contudo, para Lee essa interferência precisa ser mediada por uma racionalidade propriamente histórica, a partir de critérios de análise e formulação que refuguem os usos interessados do passado.

Em síntese, para Lee o passado se torna mais histórico quanto menos ele for mobilizado na direção de uma utilidade presente, já para Rüsen é inevitável que as interpretações históricas refiram-se ao presente, sendo o mais equilibrado que elas apreendam as diferenças temporais e sua significação se dê em torno da ideia de mudança, ou da diferença temporal, para que o passado não determine o presente, apenas o influencie. Assim sendo, Lee separa as duas dimensões epistemológicas da História, entre uma operacional e outra utilitária, enquanto Rüsen apresenta as duas como complementares e indissociáveis.

Nesse sentido, devemos pensar que a pragmática da Educação Histórica deva ser pensada nesse duplo sentido. Primeiramente, buscando princípios e métodos de ação que podem guiar a formulação de estratégias de ensino levando em consideração a natureza epistemológica da História num sentido estrito, ou seja, como constructo humano mediado por procedimentos e regras que garantem maior ou menor fiabilidade dos argumentos históricos. Em 
segundo lugar, estabelecendo os parâmetros que devem conduzir a organização dos conteúdos históricos para que os sujeitos utilizem o passado como critério de orientação temporal, sem que esses parâmetros impliquem em formas de condução e/ou doutrinação das identidades em sentidos que neguem a especificidade e racionalidade do pensamento histórico, tornando-se utilitaristas e politicamente interessados.

Não se trata de uma formulação fácil, pois, no fundo, o que fica em evidência é uma situação paradoxal e elementar. O processo de aprender a desenvolver uma racionalidade, propriamente histórica, implica no fato de que o conhecimento científico se organiza pela possibilidade da dúvida e da indagação constantes. Porém, não se constrói essa racionalidade no vazio, pois o aprendizado dessas categorias se dá a partir de determinadas histórias, que são construídas e reconstruídas nesse processo, ao mesmo tempo em que formam e informam as identidades dos sujeitos. Ou seja, os sujeitos aprendem a pensar historicamente enquanto aprendem História. Assim sendo, é possível questionar: a disposição de indagação e de construção das próprias referências históricas consiste num ato de liberdade do pensamento? Ou essa possibilidade se condiciona pelas referências próprias inerentes ao processo de aprendizagem? Em outros termos, os conteúdos ensinados não influenciam a forma como se constrói visões históricas, o que pode ser fator limitador da própria aquisição de uma competência de articular os conceitos mais elaborados do pensamento histórico?

Jörn Rüsen (2010) tenta equacionar essas questões ao propor o que considera o "livro didático ideal", quando define que o conhecimento histórico deve ser tratado simultaneamente como compreensão e orientação, desenvolvendo, assim, uma competência narrativa, ou seja, uma capacidade de "representar o passado com vistas à compreensão do presente". Para tal, o livro didático precisa ser "capaz de ensinar para a percepção histórica, de oferecer a possibilidade de realizar interpretações históricas corretas e estimular a orientação para a vida presente, relacionando-as com as perspectivas de futuro" (RÜSEN, 2010, p. 46). 
Para cumprir tais objetivos, Rüsen (2010) propõe que o livro estimule a percepção histórica, oferecendo fontes que facilitem a percepção sensorial da diferença temporal, apresentando, sincrônica e diacronicamente, as experiências históricas, de uma forma multiperspectivada, abrindo para as várias possibilidades de interpretação histórica e superando uma visão linear e homogênea dessas experiências. Rüsen entende, também, que deva ser favorecida a interpretação histórica, desde que essa interpretação corresponda aos princípios da ciência histórica, desenvolvendo capacidades de manuseio das metodologias de investigação, favorecendo a compreensão do caráter processual e perspectivado dessa interpretação e apresentando visões inteligíveis e convincentes, que não confundam juízos e fatos, hipótese e juízos de valor, trazendo uma percepção clara do passado, sem excessiva emotividade.

Rüsen entende, também, que os livros devem estimular a orientação histórica, possibilitando a reflexão do aluno sobre suas identidades, evitando certa imparcialidade que signifique a isenção e não tomada de posição, que consistiria na relativização do conhecimento e não no seu embasamento para constituição de sentidos no tempo. Também entende que se deve estimular esses juízos históricos, ou tomadas de posição, desde que sejam embasados e façam referências ao presente.

Em síntese, a ideia de "livro didático ideal" de Rüsen traz elementos teóricos interessantes para reflexão sobre o Ensino de História. Esse autor tenta fundir os dois elementos da epistemologia da História para os quais chamamos a atenção, a questão da fundamentação e controle dos resultados da investigação histórica, e a questão dos usos e práticas em torno desses resultados na construção das identidades e do agir dos indivíduos. Enfatizamos que Peter Lee não adere completamente a essa tese, uma vez que tem ressalvas quanto à possibilidade integral de fusão entre essas duas dimensões. Contudo, é importante enfatizar esse debate teórico como elemento chave da investigação que propomos, que se constitui nesses dois polos. Por um lado, entender como os livros didáticos entendem a natureza epistemológica da 
História. Por outro, como pensam na relação entre ciência e vida, ou seja, entre a construção do conhecimento e sua relevância na vida social e individual dos sujeitos. Na sequência, esse artigo tomará um conjunto de livros didáticos de História como fontes para analisar essa problemática específica. O intuito, a princípio, é evidenciar como essas questões estão dispersas no ensino, sendo tratadas de forma dissociada, como se uma questão não tivesse relação com a outra. Essa dispersão, por outro lado, leva ao âmago da problemática a que nos referimos, qual seja, a ausência de uma pragmática da Educação Histórica que leve a sério a dupla natureza epistemológica da História.

\section{Um estudo sobre livros didáticos e epistemologia da História}

O estudo realizado analisou sete coleções didáticas, publicadas entre 2008 e 2015, e foi estruturado a partir de dois questionamentos: Como a obra aborda a questão epistemológica do conhecimento histórico? De que forma é tratada a questão das finalidades da aprendizagem histórica?

Por tratar-se de um estudo exploratório, a seleção se deu em decorrência da disponibilidade de acesso às coletâneas. Contudo, consideramos que essa amostragem, apesar de aleatória, pode ser considerada representativa, pois o padrão encontrado nas sete coleções analisadas não se diferencia muito do que pode ser observado na maioria das coleções disponíveis no mercado editorial, pois essas obras seguem um padrão, mais ou menos regular, de abordagem das questões apresentadas.

As obras analisadas estão apresentadas na tabela abaixo:

Quadro 1 - Obras analisadas

\begin{tabular}{|l|l|l|l|}
\hline Coleção & Autor(es) & Editora & Ano \\
\hline Perspectiva história, & $\begin{array}{l}\text { Renato Mocellin e Rosiane } \\
\text { Camargo. }\end{array}$ & $\begin{array}{l}\text { Ed. } \\
\text { Brasil }\end{array}$ & 2012 \\
\hline História - Sociedade \& Cidadania & Alfredo Boulos Junior & FTD & 2009 \\
\hline Saber e fazer história & Gilberto Cotrim e Jaime & Saraiva & 2012 \\
\hline
\end{tabular}




\begin{tabular}{|l|l|l|l|}
\hline & Rodrigues & & \\
\hline Jornadas. Hist - Historia & Silvia Panazzo e Maria Luísa Vaz & Saraiva & 2012 \\
\hline Para viver juntos: história & $\begin{array}{l}\text { Debora Motooka e Muryatan S. } \\
\text { Barbosa }\end{array}$ & SM & 2008 \\
\hline $\begin{array}{l}\text { Estudar História: das origens à } \\
\text { era digital }\end{array}$ & Patrícia Ramos Braick & Moderna & 2015 \\
\hline História.doc & Ronaldo Vainfas & Saraiva & 2015 \\
\hline
\end{tabular}

Fonte: Estudo empírico, acervo do autor.

Por tratar-se de estudo qualitativo, de natureza exploratória, realizamos uma análise de conteúdo centrada nas características gerais das obras e na forma como as questões colocadas eram abordadas explicitamente. Nesse sentido, outros estudos, mais específicos e abrangentes, poderiam confirmar o que aqui constatamos ou reorientar as conclusões. Entretanto, o trabalho realizado busca levantar questões, e não trazer conclusões definitivas.

Na sequência, apresentamos os resultados das análises a partir dos dois questionamentos formulados, e essa apresentação se dará com uma visão do todo. Ou seja, não focaremos nas diferenças nem nos pormenores de cada coleção, mas em observar como essas questões são respondidas de forma central pelas fontes analisadas, ressaltando as similaridades e tendências gerais, que podem revelar padrões.

\section{Como é abordada a questão epistemológica do conhecimento histórico?}

Nas coleções analisadas, há coincidência de abordagem ao tratar da natureza própria do conhecimento histórico, pois todas destinam um capítulo específico à questão. A temática aparece abrindo as coleções, no volume destinado ao sexto ano do ensino fundamental. Trata-se, em todos os casos, do primeiro conteúdo a ser abordado pelo(a) professor(a), como forma de "introdução" ao estudo da História. Em apenas um caso esse conteúdo aparece 
mesclado com a questão da origem da humanidade e do estudo da PréHistória, como partes de um mesmo capítulo. Nos demais, há sempre um ou dois capítulos específicos para o assunto.

Essas introduções, geralmente, são subdivididas em tópicos específicos que se repetem nas diferentes coleções, os quais sintetizamos nas seguintes categorias: 1. História como historiografia acadêmica; 2. História como experiência individual; 3. História como organização e contagem do tempo. As três categorias, que não são indissociáveis num debate epistemológico mais abrangente sobre a História, geralmente aparecem separadas nos livros, que organizam esses conteúdos, a partir de algumas características comuns.

Uma primeira abordagem que se repete em todas as coleções trata-se, de modo geral, da ideia de responder à pergunta "O que é História?", apresentando como resposta o trabalho do historiador. Em apenas uma coleção a questão aparece como atividade investigativa sobre o tempo sem restringi-la e centralizá-la na figura do historiador. Essa definição da História como produto da pesquisa histórica se realiza ao centrar a explicação sobre o conceito de fonte histórica, descrevendo, de forma superficial, tipologias de fontes e metodologias de investigação. Em alguns casos, mais raros, há um aprofundamento sobre elementos centrais da ciência histórica, como a seletividade e perspectividade do conhecimento, assim como um aprofundamento dos conceitos de evidência e interpretação histórica.

Essa forma de tratar a História chama a atenção por dois aspectos relevantes. Primeiramente, quando inicialmente propõe-se que a História se trata do trabalho do historiador, cria-se certa oposição a outro tópico comum, sobre a ideia de que a História também faz parte do processo vivido. Nesse sentido, há uma clara dissociação entre, por um lado, os produtos do trabalho do historiador, que investiga o passado a partir de determinadas metodologias e apresenta seus resultados sob a forma de escritos históricos, e, por outro, a passagem do tempo na vida social, que é vivenciada e sentida pelos indivíduos. Nesse segundo caso, é comum recorrer-se ao conceito de memória, individual ou social, como base para tratar dessa percepção da 
passagem do tempo e as formas através das quais ela se manifesta, na vivência das pessoas e na convivência dos grupos humanos.

Outra dissociação, que chama a atenção, trata-se do fato de que o trabalho do historiador é entendido como processo investigativo que resulta em determinadas constatações, publicizadas e aceitas sob a forma de conhecimento histórico autorizado. Entretanto, nesses mesmos livros didáticos há uma exposição de conteúdos históricos que não revela a autoria. Sendo assim, os conteúdos são tratados como conhecimentos tácitos de domínio público, pois não se fazem referência aos historiadores que os produziram. Nota-se, então, uma evidente contradição na qual os manuais apresentam o conhecimento histórico como produto da investigação, mas depois expõem seu conteúdo como conhecimentos dados, herdados de alguma forma de tradição social de saberes sobre o passado, ou seja, sem fazer qualquer menção aos processos de pesquisas que resultaram naqueles conhecimentos.

A terceira categoria também aparece separada das duas primeiras, sem explicitarem-se os vínculos entre elas. Nesse caso, os livros apresentam, comumente, o calendário gregoriano como forma padrão de contagem do tempo histórico na cultura Ocidental. Em alguns casos há comparação com outros calendários, como indígenas ou muçulmano, mas ainda assim mantendo por base a ideia de que há certo tempo histórico contido nos calendários, a partir dos quais os eventos são datados e organizados, remetendo a uma espécie de regularidade temporal.

Novamente, nota-se uma incongruência elementar. Os calendários são produtos de determinada tradição, resultantes de uma convenção a partir da qual se torna possível certa orientação cultural por meio dos marcos temporais. Contudo, se a História é produto da investigação dos indivíduos e também pode ser compreendida como processo vivido, os calendários e a contagem do tempo também são produtos de criações humanas, mas são apresentados como entidades dadas.

Esses elementos revelam uma abordagem dicotômica do conhecimento histórico, que se repete em todas as coleções. De um lado, há o conhecimento 
histórico autorizado, metódico, que ofereceria produtos de conhecimento "qualificados". De outro, há a experiência dos indivíduos, assim como a experiência social, que raramente têm relação com a primeira categoria, por não haver controle do que delas deriva.

No próximo tópico, avançaremos em outro ponto do debate epistemológico a respeito da História que, para além da questão sobre como se constrói o conhecimento histórico, discute, também, quais os impactos desse conhecimento na orientação social e cultural dos indivíduos.

\section{Quais as finalidades da aprendizagem histórica?}

Uma segunda análise diz respeito a como essas obras respondem à pergunta "por que e para que aprender História?". Abordar as finalidades da aprendizagem histórica trata-se de uma importante reflexão epistemológica, pois diz respeito a como o conhecimento é pensado e apropriado pela cultura, e se serve a interesses puramente cognitivos ou se essa apropriação se dá em outras direções, voltadas a outros interesses, como político-ideológicos. Se a opção for essa, cabe, ainda, a reflexão epistemológica no sentido de imaginar de que forma o conhecimento responde ou não a essas demandas, ou seja, se essas apropriações são da natureza própria do conhecimento ou se se constituem como sua mutilação ou uso arbitrário.

Para essa segunda parte do estudo levamos em consideração o que as próprias coleções afirmam como tais finalidades. Ou seja, não buscamos verificar a correspondência entre a proposta e a efetivação da proposta, mas apenas as intenções, que expressam as visões daqueles que os produzem e, de alguma forma, alguma adesão dos que os utilizam. Nesse caso, encontramos três padrões comuns de repostas: 1. Perceptiva ou compreensiva: compreender $o$ presente, perceber mudanças e permanências; 2. Indenitária ou subjetiva: para que os indivíduos se percebam como sujeitos históricos; 3. Motivacional ou transformativa: mobilizar os sujeitos na construção de uma sociedade mais justa. 
$\mathrm{Na}$ primeira categoria, a mais presente, que classificamos como perceptiva ou compreensiva, observamos, primeiramente, a noção segundo a qual o conhecimento histórico é dotado da possibilidade de reunir dados que permitam compreender a realidade na qual se vive, como no trecho a seguir, extraído de um dos livros analisados:

[...] compreender a realidade atual com base no estudo do passado. Esse estudo permite entender as sociedades anteriores a nossa, com suas diferenças e particularidades, como fruto de seu tempo e da ação de seus sujeitos. Possibilita, ainda, percebermos como as ações de diferentes pessoas e povos, em diferentes lugares, influenciaram e continuam influenciando o presente (MOTOOKA; BARBOSA, 2008).

Do ponto de vista da discussão epistemológica que propomos, compreender a realidade do presente com base no passado se constitui como um desafio, ou armadilha, em dois sentidos elementares. O primeiro, que por ser seletivo e perspectivado, o conhecimento histórico sempre será lacunar, não cobrindo o todo das experiências passadas que poderia gerar compreensões consensuais do presente. O segundo, porque o próprio conceito de realidade presente é passível de uma série de questionamentos, pois se deve ter em conta a complexidade dos feitos humanos e das possíveis interpretações sobre esses feitos.

A segunda forma dentro dessa categoria da percepção ou compreensão consiste naquela que defende o conhecimento histórico com a finalidade de perceber mudanças e permanências. Apesar dessa opção ser mais plausível que a primeira, do ponto de vista da epistemologia da História, há ainda desafios, pois a percepção das mudanças e permanências depende de um engajamento do indivíduo e de uma seleção educativa. Ou seja, quais mudanças e quais permanências interessam ao processo educativo e quais mudanças e permanências dizem respeito ao indivíduo que aprende, qualificando sua formação histórica?

A segunda categoria identificada ao tratar das finalidades da Educação Histórica, denominada indenitária ou subjetiva, propõe que a História deva 
tratar da construção da autoimagem dos alunos para perceberem-se como sujeitos históricos, além de inseri-los como participantes e promotores desse conhecimento. A centralidade do processo está no vínculo que os alunos estabelecem com a História, identificando-se com seus sujeitos e, simultaneamente, sentindo-se participantes do fluxo temporal.

Nesse caso, cabe levantar algumas problemáticas. Se a princípio a pesquisa histórica é o cerne da construção do conhecimento histórico, que tipo de princípio fundamenta uma pesquisa centrada nos processos de construção da subjetividade? É possível falar em uma centralidade da subjetividade na construção do conhecimento histórico? Essa visão não compromete a própria visão da natureza da ciência histórica como produto de interesse coletivo? Os questionamentos são abertos e abrangentes, e não há pretensão de respondêlos, pois as obras não trazem elementos para construir essa análise, por isso trazemos essas problemáticas a título de reflexão geral.

Uma terceira forma de abordar as finalidades da aprendizagem histórica situa-se sobre uma visão transformativa ou motivacional. Neste caso, as obras geralmente apresentam que a História tem por finalidade levar o aluno a reconhecer a necessidade de lutar por uma sociedade mais justa, exercer tolerância e respeito, o que favoreceria a transformação social por meio das tomadas de posição individuais. Como neste exemplo: "O estudo da História pode despertar a consciência de cada um de nós para a tarefa de construir uma sociedade mais justa, com menos desigualdade entre as pessoas" (MOCELLIN; CAMARGO, 2012). Ou neste outro: "Estudar história é um passo decisivo para despertar a consciência cidadã de cada um, estimular a valorização da liberdade individual, o combate às desigualdades sociais e a luta contra todo o tipo de preconceito" (VAINFAS, 2015).

Essa terceira categoria não é a mais presente, mas é muito relevante, porque tenta estabelecer um vínculo, não muito explícito, entre a aprendizagem da ciência histórica e sua utilidade para a vida dos sujeitos. Entretanto, novamente caberia uma problemática elementar: há um processo simples e direto de assimilação de conhecimentos históricos e motivação para 
o agir dos indivíduos num sentido controlável? Ou seja, essas finalidades da aprendizagem histórica revelariam uma possibilidade efetiva e previamente identificável, ou apenas uma expectativa dos autores? Pensando nessas problemáticas, o desafio de construção de uma pragmática da Educação Histórica, conforme já se definiu neste artigo, é central.

\section{Considerações Transitórias}

Dados os resultados do estudo realizado, as considerações, por ora transitórias, direcionam-se a uma terceira questão que pode ser levantada para uma próxima investigação: Há, de forma explícita, uma relação direta entre a abordagem epistemológica da História e suas finalidades educativas? De forma indiciária, a partir do que observamos no percurso deste trabalho, a hipótese mais provável é que não há essa definição.

Esse entendimento se dá em razão de alguns detalhes observados nas obras. Primeiramente, o que chama atenção é o fato de que os conteúdos dispostos ao longo das coleções aparecem, geralmente, como conhecimentos tácitos dados por alguma tradição social e não como resultado de investigações metódicas de historiadores. Ou seja, a noção geral que os livros deixam transparecer é que o conhecimento histórico se trata de um saber pacificado, e que os conteúdos das coleções seria a síntese desses saberes já consolidados, sem atentar-se à própria natureza seletiva, controversa e multiperspectivada do conhecimento histórico.

Outro ponto relevante se trata do fato de que as obras apresentam apenas considerações gerais e superficiais, com uma compreensão rasa sobre os desafios epistemológicos da ciência histórica, o que pode levar à instrumentalização da ciência em nome de objetivos externos a sua racionalidade específica. Ou seja, de um lado, há uma preocupação em classificar a História como conhecimento aberto, multiperspectivado e resultante de uma racionalidade investigativa fundamentada. De outro, entretanto, o que se tem, enquanto propostas pragmáticas consiste em 
conjuntos de conteúdos dados a priori a partir de objetivos outros, não necessariamente comprometidos com os fundamentos epistemológicos desta ciência de referência.

Cabe ressaltar que esse estudo deriva de uma análise geral, uma visão panorâmica e indiciária, e o que apresenta é um olhar transversal sobre as obras, de forma a trazer elementos que subsidiem um conjunto de constatações iniciais. Essas constatações podem encaminhar novos estudos, que aprofundem questões e permitam olhares mais específicos, especialmente na forma como os livros didáticos abordam os conteúdos históricos e sua natureza como produtos da pesquisa histórica, identificando autorias, tendências e bases teóricas.

Essas preocupações também poderiam conduzir a estudos de outra natureza, que observassem os usos e apropriações dessas ideias pelos sujeitos do universo escolar como, por exemplo, de que forma as práticas dos(as) professores(as) se aproximam ou se distanciam da questão da epistemologia da História, ou como os estudantes assimilam essas questões e que ideias a respeito da ciência histórica eles constroem no trabalho com esses materiais.

Entretanto, por mais que esses questionamentos abram um leque importante de possibilidades investigativas, o presente artigo levanta uma problemática geral, sobre a forma como a epistemologia da História está presente nos livros didáticos. E o que se identificou foi a forma superficial e dicotômica a partir da qual a História é apresentada. As questões são tratadas de forma meramente ilustrativa em materiais dedicados a crianças de 11 e 12 anos de idade.

Uma pragmática da Educação Histórica precisa ser orientada, fundamentalmente, por objetivos de aprendizagem que estejam conectados aos fundamentos da racionalidade histórica, e que as proposições e estratégias didáticas não podem centrar-se em fatores. Nesse sentido, um caminho de avanço nos estudos sobre manuais didáticos e epistemologia da História, consistiria em verificar de que forma as proposições pedagógicas ao longo das coleções dialogam com esses elementos da epistemologia da História, seja no 
conteúdo dos textos, nos materiais apresentados ou indicados, no trabalho com imagens, nas atividades e reflexões propostas.

Em síntese, a contribuição desse artigo consistiu em proporcionar aos investigadores que se ocupam do ensino esse olhar sobre a natureza e as funções do conhecimento histórico, e conduzam a um compromisso com História como ciência, contra sua instrumentalização e a favor de princípios básicos no trato com o passado. Para isso, os manuais didáticos são fontes centrais do trabalho, e devem ser analisados, indagados e criticados, no sentido de proporcionar avanços para uma nova pragmática da Educação Histórica.

\section{Referências}

BOULOS JUNIOR, Alfredo. História: Sociedade \& Cidadania, $6^{\circ}$ Ano. São Paulo: FTD, 2009.

BRAICK, Patrícia Ramos. Estudar História: das origens à era digital. 2. ed. São Paulo: Moderna, 2015.

CHAVES, Edilson Aparecido; GARCIA, Tânia Maria F. Braga. Critérios de escolha dos livros didáticos de História: o ponto de vista dos jovens. In: CONGRESSO NACIONAL DE EDUCAÇÃO - EDUCERE, 10. 2011, Curitiba. Anais... Curitiba: PUCPR, 2011. p. 9758-9769.

COTRIM, Gilberto; RODRIGUES, Jaime. Saber e fazer história, $6^{\circ}$ Ano. 7. ed. São Paulo: Saraiva, 2012.

CUESTA FERNANDEZ, Raimundo. Clío en las aulas: la enseñanza de la Historia en España entre reformas, ilusiones y rutinas. Madrid: Ediciones Akal, 1998.

FORQUIN, Jean-Claude. Escola e Cultura: as bases sociais e epistemológicas do conhecimento escolar. Porto Alegre: Artes Médicas, 1993.

JULIA, Dominique. A cultura escolar como objeto histórico. Revista Brasileira de História da Educação, n. 1, p. 9-43, jan./jun. 2001.

LEE, Peter. Literacia Histórica e História Transformativa. Educar em Revista, Curitiba, Brasil, n. 60, p. 107-146, abr./jun. 2016.

MEDEIROS, Daniel H. Manuais Didáticos e Formação da Consciência Histórica. Educar, Curitiba, Especial. p. 73-92, 2006. 
MOCELLIN, Renato; CAMARGO, Rosiane. Perspectiva história. 2. ed. São Paulo: Ed. do Brasil, 2012.

MOTOOKA, Debora Y.; BARBOSA, Muryatan Santana. Para viver juntos: história, 6Ano. 3. ed. São Paulo: SM, 2008.

PANAZZO, Silvia; VAZ, Maria Luísa. Jornadas História, $6^{\circ}$ ano. 2. ed. São Paulo: Saraiva, 2012.

RÜSEN, Jörn. História viva. Teoria da história III: formas e funções do conhecimento histórico. Tradução de Estevão Rezende Martins. Brasília: Ed. UNB, 2007.

RÜSEN, Jörn. Jörn Rüsen e o ensino de história. Curitiba: Ed. UFPR, 2010.

RÜSEN, Jörn. Que es la cultura historica?: reflexiones sobre uma nueva manera de abordar la historia. Tradução de: SÁNCHEZ COSTA, F.;

SCHUMACHER, I. B. Original In: FÜSSMANN, K.; GRÜTTER, H. T.; RÜSEN, J. (ed.). Historische faszination. geschichtskultur heute. Viena: Böhlau, 1994. p. 3-26.

RÜSEN, Jörn. Razão histórica. teoria da história: os fundamentos da ciência histórica. Brasília: UNB, 2001.

SCHMIDT, Maria Auxiliadora. Cognição histórica situada: que aprendizagem histórica é esta? In: SCHMIDT, Maria Auxiliadora; BARCA, Isabel. Aprender história: perspectivas da educação histórica. Ijuí: Ed. Unijuí, 2009. p. 21-51.

URBAN, Ana Cláudia. Didática da História: percursos de um Código Disciplinar no Brasil e na Espanha. Curitiba, 2009. 246 f. (Tese de Doutorado). Universidade Federal do Paraná.

VAINFAS, Ronaldo et al. História.doc, $6^{\circ}$ ano. São Paulo: Saraiva, 2015.

VALLS MONTÉS, Rafael. Los estudios sobre los manuales escolares de historia y sus nuevas perspectivas. Didáctica de las ciencias experimentales y sociales, n. 15, p. 23-36, 2001.

WILLIAMS, Raymond. La larga revolución. Tradución de Horacio Pons. Buenos Aires: Nueva Visión, 2003.

WILLIAMS, Raymond. Marxismo e literatura. Rio de Janeiro: Zahar, 1979. 
Recebido em 31 de outubro de 2018 Aprovado em 19 de dezembro de 2018 